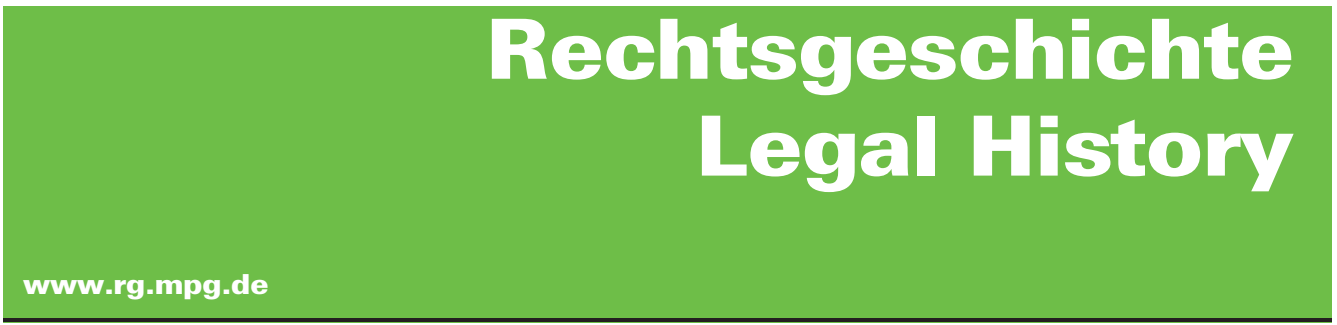

http://www.rg-rechtsgeschichte.de/rg20

$\mathrm{Rg} 2012 \quad 418-419$

Zitiervorschlag: Rechtsgeschichte - Legal History Rg 20 (2012)

http://dx.doi.org/10.12946/rg20/418-419

\title{
Thomas Gergen
}

\section{Zwischen Lateinisch und Katalanisch}

Juristische Translation im mallorquinischen Buch der Könige 
nach 1945, steht m. E. stärker im Zeichen einer Ausweitung der Warenverbältnisse in alle Felder der Zirkulation der immateriellen, symbolischen Güter. Mittelalter-Imaginationen unterliegen nun einer Wandlung von Orientierungsideen zu Unterhaltungspartikeln. Dadurch entsteht eine m. E. neuartige Unbegrenztheit der mediävalen Aufrufungen, derer sich eine von sich selbst emanzipierte Mediävistik - als Mediävalistik? - mit kritischer Verve anzunehmen hätte. Um beide Fortspinnungen begrifflich aufzunehmen: Ich würde mich noch mehr auf die Semantik der Entzweiungszeit der Mittelalterideologie und auf den Konsumwert fiktiv mittelalterlicher Unterhaltungsstoffe konzentrieren.

Zuletzt noch ein innerdisziplinäres Argument zur Bewältigung der Krise der gebeutelten Mediävistik. Viel zu wenig gesprochen und geplant wird noch über die Erschließung der prall gefüllten archäologischen Depots in Hunderten von Museen und der mittelalterlichen Bau-und Bild-Monumente allerorten einerseits, und über die statistische Aufarbeitung digitalisierter Dokumentbestände andererseits. Was da »wartet «, ist im Grunde kaum geheuerlich. Eine energische Erweiterung um diese Aufgabenfelder würde nicht nur das »verstehende« Durchschnittsgebaren der Mediävistik herausfordern, sondern ihr auch höhere Akzeptanz in der kulturpolitischen Öffentlichkeit bescheren - eine methodische und funktionale Modernisierung steht an. Aber diese Pisten technischer und sachlicher Erneuerungen der Mediävistik waren, zugegeben, nicht Groebners Thema. Sein Verdienst: die programmatische Verklebung von Mediävismus und Mediävistik. Sie ist und bleibt auf der Agenda!

\title{
Thomas Gergen
}

\section{Zwischen Lateinisch und Katalanisch}

\author{
Juristische Translation im mallorquinischen Buch der Könige*
}

"Buch der Könige« (Llibre dels Reis) nannte Josep Maria Quadrado kurz und prägnant das "Buch der Freiheiten und Privilegien des Königreichs Mallorca«, nachdem er es im Jahre 1840 entdeckt hatte. Seine Edition des Códice de los Reyes, o sea, el Rey de los Códices en el Archivo de Mallorca folgte allerdings erst in der Zeitschrift »Museo Balear de Historia y Literatura, Ciencias y Artes« von 1886 (S. 361-392). Lange Zeit war das Buch aus der Entstehungszeit zwischen den Jahren 1334 und 1341 wenig beachtet, allenfalls wurde seine hochwertige Bebilderung zur Kenntnis genommen. Der vorliegende Band schließt nunmehr diese lang anhaltenden Forschungs- und Wissenslücken in kultur-, kunst-, archiv- und vor allem rechtshistorischer Hinsicht. Er beinhaltet Studien und Transkriptionen der Freiheiten und Privilegien aus katalanischen und lateinischen Repertorien sowie eine katalanische Version der Usatges de Barcelona. Die Usatges waren schon seit der Carta de població von 1230 geltendes Straf- und Strafprozessrecht im Königreich Mallorca, denn Kapitel 14 besagte: "in causis iniuriarum, dampnis vulneribus illatis, procedatur secundum Usaticum Barchinone«. Um besser zu verstehen, wie der Rechtskosmos zur Zeit der Redaktion des Buches der Könige ausgesehen hat, ist es nötig, den König selbst in seiner Zeit zu charakterisieren: Jaume III. von Mallorca (geboren 1315 in Catania), der in der Schlacht von Llucmajor im Jahre 1349 starb, kon-

* Llibre dels Reis. Llibre de franqueses i privilegis del regne de Mallorca (Còdex número 1 de l'arxiu del regne de Mallorca), Estudis i transcripcions, dir. de Ricard Urgell Hernández, Palma de Mallorca: Ed. UIB [u.a.] 2010, 415 S., ISBN 978-84-9716-697-3 
zedierte seinen Untertanen zahlreiche Freiheiten, die die Geschworenen (jurats) der Stadt und des Königreichs von Mallorca aus verschiedenen Quellen (»dispersi posita in diversis cartis et scripturis") zusammen stellten, um sie davor zu bewahren, in Vergessenheit zu geraten. Es handelt sich um eine für Mallorca einzigartige und frühe Rechtsaufzeichnung. Gleichwohl ist bekannt, dass das Buch der Könige schon Vorläufer hatte; denn 1288 sandten die Geschworenen von Ibiza Guillem de Banyoles nach Mallorca, um die von Jaume I. eingeräumten Freiheiten zu notieren. Außerdem war es stets wichtig, dass mallorquinische Kaufleute die Privilegien ihres Herkunftslandes, wie etwa Steuerprivilegien, in anderen Ländern beweisen konnten, um dort keine Rechtsnachteile zu erleiden; dies konnten sie im Allgemeinen mit Hilfe von Rechtssammlungen tun.

Der Kodex 1 des "Arxiu del Regne de Mallorca" zerfällt in zwei Teile: Der erste enthält eine Sammlung von durch das Königreich Mallorca konzedierten Privilegien und Freiheiten. Diese sind in der Originalsprache auf Lateinisch verfasst, während der zweite Teil vornehmlich ins Katalanische übersetzte Privilegien umschließt. Ein Vergleich des ersten mit dem zweiten Teil lässt indes erkennen, dass nicht einfach vom Lateinischen ins Katalanische übersetzt wurde, sondern dass 13 Bestimmungen, die zwischen den Jahren 1279 und 1325 entstanden waren, sich nicht im lateinischen Text finden. Herausgearbeitet werden kann, dass die Dokumente in beiden Teilen bzw. Sprachen nicht in strenger chronologischer Reihenfolge angeordnet sind, was auch beweist, dass in beiden Sprachen gleichzeitig gearbeitet und gewissermaßen simultan übersetzt worden sein musste. Die von Jaume I. und Jaume II. in der ersten Phase seiner Regentschaft verliehenen Privilegien wurden schon zu Ende des 13. Jahrhunderts ins Katalanische übersetzt. Die Bestimmungen dieser Monarchen, welche im Llibre de la cadena von Ibiza zusammengeführt worden waren (das wiederum anhand eines Kodex, den 1288 die Konsuln in Mallorca besaßen, verfasst wurde), erfuhren ebenso eine katalanische Übersetzung und standen mithin bereits in katalanischer Sprache zur Verfügung. Kritisch anzumerken bleibt, dass der Leser vielleicht mehr Details zu den angewandten Kriterien hinsichtlich der Sprachenauswahl erwartet hätte; hier liegt m.E. noch ein Desiderat.

Wann wurde der im Vergleich zu anderen Kodizes reich bebilderte Kodex in der Rechtspraxis angewandt? Vermutlich vor allem bei feierlichen Gelegenheiten wie Eidesleistungen von Amtsträgern. Dafür spricht, dass zwischen lateinischer und katalanischer Version man neben den Usatges de Barcelona und einer Kurzchronik auch einige Fragmente der Evangelien zwecks Eidesleistung sowie einen liturgischen Kalender mit einer Tafel findet, mit der jeweils das Osterfest bestimmt werden konnte. Dass der Kodex für die »Universitas Civitatis et Regni Maioricarum « verfasst war, resultiert auch daraus, dass er im Unterschied zu früheren und zeitgleichen Kodizes nicht bloß die katalanische Version, ggf. mit lateinischer Übersetzung, sondern an erster Stelle den lateinischen, gefolgt an zweiter Stelle von einer katalanischen Version enthält, die wiederum leichteren Zugang zur Materie ermöglichte. Die deutlich sichtbaren Marginalglossen verraten des Weiteren einen gewissen, nicht allttäglichen Gebrauch des Kodex in der Rechtspraxis. Keinesfalls sollte das Buch eine vollständige Sammlung des gesamten mallorquinischen Rechtes sein, sondern bildete die Freiheiten und Privilegien ab, die die Einwohner der Stadt und des Königreiches von Mallorca, also die »Universitas Civitatis et Regni Maioricarum «, begünstigen sollten. Das Buch vereint das damalige konzedierte Recht und sollte künftig als Quellengrundlage für Einzelstudien stets herangezogen werden. 